\title{
China's Policy on Rural-urban Migrants and Urban Social Harmony
}

\author{
Ying Li (Corresponding author) \\ Ph.D, School of Labor and Human Resources, Renmin University of China \\ No. 59 Zhongguancun Avenue, Beijing 100872, China \\ E-mail: liyingkate@hotmail.com \\ Ernest Chui \\ Associate Professor, Department of Social Work \& Social Administration \\ The University of Hong Kong, Pokfulam Road, Hong Kong, China \\ Tel: 852-2-859-2092Ｅ-mail: ernest@hku.hk
}

Received: January 7, $2011 \quad$ Accepted: February 24, 2011 doi:10.5539/ass.v7n7p12

\begin{abstract}
Rural migrants have suffered from serious social exclusion in the Chinese urban society. However, since the early 2000s, the Chinese government emphasizes social harmony as an important national development goal. Together with the reorientation of development goals, the livelihood of rural migrants has received unprecedented State attention. This paper studies the policy changes and examines whether they have enhanced urban social harmony, particularly, in improving the welfare of rural migrants. It was found that the policy changes only partially restored the social and political rights of rural migrants. Some rural migrants have resorted to extreme actions, such as suicides, crimes, and strikes, to express their grievances, thereby contradicting government attempts to ensure social harmony. Further efforts are required to enhance the social inclusion of rural migrants in urban China.
\end{abstract}

Keywords: Social inclusion, Social harmony, Rural-urban migrant workers, China

\section{Introduction}

China has devoted itself to promoting economic growth, gaining tremendous successes in the past 30 years. However, accompanying such rapid economic growth is the evident rise in social problems. In the early 2000s, the Chinese government has redefined its developmental goals and strategies, one of which is placing more emphasis on social harmony while continuing its efforts to promote economic growth [China Communist Party Central Committee (CCPCC), 2004]. By "social harmony," the State claims to solve problems concerning people's basic interests, enabling them to enjoy the fruits of reform and development more equally, as well as to gain from a strengthened democracy and legal system. The "people first" approach, social equality, social stability, and social cohesion are underlined as the key principles and goals (CCPCC, 2005).

With this shift in developmental goals, the State has reformulated its social policies, including its policies towards rural-urban migrants. Rural-urban migrants, a major driving force in China's economic prosperity, constitute a huge social group in contemporary China. By the mid-2000s, nearly 120 million rural laborers (more than $20 \%$ of the total rural labor force) moved to the urban areas to seek employment opportunities (The Drafting Group of the Report of Rural-Urban Migrant Workers, 2006, p.4). However, rural migrants have experienced severe social exclusion in urban China; this is counterproductive to social harmony.

This paper aims to explore the effects of current government policies for rural migrants that are aimed at enhancing social harmony. Document analysis is employed to achieve this research purpose. It examines specific policy changes for rural-urban migrants that commenced since the early 2000s and their effects on the livelihood of rural migrants. In this paper, special attention would be given to the different actions of rural migrants facing unequal treatment, as such is closely related to social order and stability.

This paper will firstly review the different forms of discrimination against rural migrants in the 1980s and 1990s. Then, it focuses on the new policies for rural migrants beginning the early 2000s, and examines the results of 
policy implementation to gauge whether such policies had enhanced the rural migrants' rights and interests. Next, the action of rural migrants is elaborated. Based on this examination, this paper finally discusses whether the policy changes since the early 2000s have enhanced social harmony and social inclusion. The paper concludes by providing recommended improvements on the said policy changes.

\section{Social Exclusion of Rural-Urban Migrants in the 1980s and 1990s}

Rural-urban migration gained momentum in China in the mid-1980s. The government implemented a series of policies to adapt to this new phenomenon, but its policies have been heavily constrained by an institutional legacy from the planned economy, namely, the hukou system (i.e., household registration). This system segregated rural populations from urban residents, granting different state welfare entitlements between the two. Generally, urban residents were provided a wide range of social services and welfare, while rural residents largely had to fend for themselves. Under this system, to avoid any negative impacts to the urban society, rural laborers were allowed to work in cities in the 1980s and 1990s. However, they were not permitted to transfer their hukou and, consequently, had no social entitlements in their host city. In addition to their limited social rights, rural-urban migrants did not have equal political rights with local urban residents. In China, people's political rights, such as the right of election, are also linked to their hukou. As rural migrants had no local hukou in their host cities, they could not take part in the elections.

What is more, the sudden expansion of rural-urban migration at the end of the 1980s had an impact on urban infrastructure and social administration, especially in the coastal cities that have attracted large numbers of migrants. As a result, the Chinese government had promulgated various regulatory policies in the 1990s to manage the employment and residence of rural migrants in urban China $\left(\mathrm{Li}_{\mathrm{a}}, 2005\right)$. For example, a permit system was set up and rural-urban migrants were required to obtain various official permits and proof cards regarding their residence, employment, health status, among others. They also had to pay fees for these permits. To ensure that local residents would find employment ahead of the migrants, the latter were restricted from entering some occupational categories. In addition, a confinement and repatriation policy was also imposed on rural-urban migrants; that is, migrants without employment permits, temporary residence cards, or any other required proof would be confined by the municipal government and sent back to the countryside.

In practice, local officials are responsible for enforcing these policies. However, many of them abused their power and discriminated against the rural migrants in the policy implementation. First, they charged rural migrants exorbitant fees when they applied for official permits for residence, employment, etc.; the charges not only covered administrative costs, but might also function as a form of revenue collection to benefit local governments or officials (Knight, Song \& Jia, 1999). This then placed heavy financial burden on rural migrants. Even worse, as mentioned earlier, rural-urban migrants without employment permits, temporary residence cards, or any other required proof were detained and then repatriated to their home of origin. In 2003, a man mistakenly identified as a rural migrant worker was detained and beaten to death by officers of a repatriation center in Guangzhou (Shen, 2003), putting the suffering of rural-urban migrants at the center of public attention.

\section{The Goal of Social Harmony and Governmental Policy for Rural-Urban Migrants since the Early 2000s}

From the end of the 1970s, the period when China embarked on market reforms, the country's aggregate economic production has increased rapidly. However, new problems also loomed, mainly, in the form of income disparities, environmental and energy problems, and inadequacy in formal social provisions and support. In this new situation, from the beginning of the $21^{\text {st }}$ century, the State redefined its national development goals and strategies. Particularly, social harmony was formally advocated as an essential part of national development (CCPCC, 2004). The "people first" approach, social equality, and social stability and cohesion underlined the key principles and goals in policymaking (CCPCC, 2005).

With the reformulation of the developmental goals, the government made substantial policy changes aimed at restoring the social and economic rights of rural migrants (State Council General Office, 2003; State Council, 2006). First, restrictions on rural migrants' employment in host cities were removed. The State also required local governments to strengthen the protection of rural-urban migrants' labor rights (e.g., minimum wage, remuneration attainment, working hours, and working safety, among others).

Second, the State has opened those occupation-related and contribution-based social programs to rural migrants. Specifically, the central government required all local governments to include rural migrants into the urban employee's social insurance programs, as this can protect the employees from income losses in cases of work injuries and health problems, as well as old age. The central government also suggested that municipal governments include rural migrants in the Housing Provident Fund (HPF) Program to help employees improve their housing standards. However, no clear requirements were provided regarding the timing and pace of rural 
migrant inclusion into the HPF, thereby leaving the policy implementation to the discretion of local governments (State Council, 2006).

Third, for social programs based on government funding, the State has demonstrated a more reserved attitude. Most of these programs remain beyond the access of rural migrants, such as the Minimum Living Security Scheme (MLSS), which can provide relief to poor residents, and housing support programs like Economic and Comfortable Housing (ECH) and Low-Rent Housing (LRH), which can provide housing subsidies to individuals facing housing difficulties. The only exception is the nine-year compulsory education (i.e., 6-year primary and 3 -year junior secondary schooling). Since 2003, the State has required local governments to provide rural migrant children with equal rights to compulsory education in the host cities. This decision to provide educational services was largely because education is critical in improving the quality of human resources, as well as in the long-term development of China. This aptly makes China to be comparable to the other 'Developmental States' in East Asia in selectively emphasizing the developmental function of education amongst various social policies (Ramesh, 2004, p.153; Aspalter, 2006).

In addition to the policy change mentioned earlier with regard to the social rights of rural migrants, the political rights of rural migrants also gained government attention since the early 2000s. One of the most notable advances is that the State began including rural migrants into the People's Congress. In China, the People's Congress at the national, provincial, municipal, county and township levels is an important institution; it votes for government leaders and determines the process of making laws at each level. However, in the 1980s and 1990s, rural migrants were fully ignored when electing delegates into the local people's congresses in their host cities. Since 2002, a few cities have tried to redress this problem by including rural migrants in the municipal congress election, and in 2007, the National People's Congress announced the participation of rural migrants in the upcoming elections at the national level (Liao, 2007).

In addition, the State made explorations to set up a standard for rural migrants to obtain local hukou, as well as the full social and political rights in their host city. In fact, since the end of the 1990s, the State encouraged small towns to lift their control on the transfer of migrants' hukou ( $\mathrm{Li}_{\mathrm{c}}, 2003$; Wang, 2004). From the mid-2000s, the State further deepened the reform by encouraging both medium- and small-sized host cities to grant incrementally local hukou to rural migrants with stable employment and residence (State Council, 2006). Furthermore, the State required local governments to give priority to distinguished rural migrants (e.g., model or advanced workers, high-grade technicians) for hukou transfer policies. As for the detailed eligibility which must be satisfied in order to confer a local hukou to rural-urban migrants, the State allowed local governments to make their own decisions based on local situations.

Overall, the reform still did not endow rural migrants with equal citizenship with local residents. However, undeniably, since the early 2000s, the social and political rights of rural-urban migrants have gained much attention. The following section examines the extent and results of policy implementation, to determine whether the policy change really enhanced social harmony.

\section{Policy Implementation in the 2000s}

The following provides a general picture of the situation of rural-urban migrants in the context of the new policy. As mentioned earlier, the new policies are aimed to strengthen the labor protection of rural migrants, provide compulsory education to rural migrants' children, and allow their participation in people's congresses. Accordingly, this paper examines how these policies have performed in reality. Then, because the State has encouraged local governments to set up selection mechanisms to endow rural migrants with local hukou, the paper proceeds to explore who among the migrants have actually obtained local hukou, as well as full social and political rights, in their respective host cities.

\subsection{Labor Rights Protection}

Since the early 2000s, the labor right protection of rural migrants has been strengthened, and some problems, such as wage delay, have been relieved. However, many problems still exist, such as long working hours without due payment and the lack of formal labor contracts (Zheng \& Huang, 2006). In addition, most rural migrants are still not enrolled in the Employee's Social Insurance of their host cities. In China, the Employees' Social Insurance system requires contributions mainly from employers (in some occasions, also from employees) to provide compensation to employees in cases of occupational injuries and health problems, as well as old age. As a result, many employers have a strong motivation to avoid enrolling migrants in order to reduce labor costs. In addition, due to the lack of knowledge and confidence of social insurance programs, some rural migrants demonstrated low level of willingness to participate in urban social insurance programs (Xu, Guan \& Yao, 2011). A survey conducted in 2005 found that only about $20-40 \%$ of rural-urban migrants were actually enrolled in 
occupational injury insurance, health insurance, and old age pension insurance schemes (Zheng \& Huang, 2006). Another survey conducted in 2006 presented a more disappointing picture, which suggested that less that $10 \%$ of rural migrants were enrolled in these urban social insurance programs (Xu, Guan \& Yao, 2011).

Evidently, urban employers who have opted to minimize labor costs should be made liable for the unsatisfactory implementation of labor rights protection. Meanwhile, opportunities for rural migrants to complain and seek help should not be ignored. Generally, rural migrants can formally resolve labor rights disputes through the following steps: First, they can ask the Labor Dispute Arbitration Committee from the local labor bureaus for intervention. Then, if the employers or rural migrants are not satisfied with the committee's decision, either of the two can file a lawsuit in court (Halegua, 2008).

However, many factors undermine the effectiveness of these formal mechanisms that are supposed to safeguard labor rights. First, both arbitration and lawsuits require time, fees, and evidences (Tong \& Xiao, 2005; Halegua, 2008). This means that if rural migrants want to safeguard their interests through these means, they have to pay the costs, not to mention the psychological pressure that they might suffer from partaking in the lawsuit. Meanwhile, urban employers often resort to delaying tactics and other means in order to increase the time and financial costs required from rural migrants, thereby pressuring the workers to yield the case (Zheng, 2005). Financial costs, long waiting time, and difficulties in acquiring the required evidence have been found as the main reasons why rural migrants avoid the formal proceedings (Tong \& Xiao, 2005).

Furthermore, the local officials, when handling labor disputes, might not treat rural migrants fairly. For example, to lower labor costs and enhance economic growth, some local officials might be biased towards the employers. Worse still, the urban employers may bribe some local officials during the arbitration of labor disputes or resort to "social relations" to influence the decisions of labor bureaus (Zheng, 2005; Halegua, 2008). In this context, many rural migrants began to doubt whether local officials could help them in their labor disputes (Tong \& Xiao, 2005).

In some cases, even if the Labor Dispute Arbitration Committee and local courts have ordered employers to provide compensation to rural migrants, these may not be enforced effectively. In fact, some employers work around the enforcement so that rural migrants would not be able to afford to wait any longer, considering the high costs of room and board in cities, thereby forcing them to return to the countryside (Zheng, 2005). In other cases, the court orders cannot be enforced at all. This often happens in the construction industry wherein construction teams were often dismissed when the project was finished, and then, usually, the courts could not find the liable parties for prosecution (Tong \& Xiao, 2005). In these cases, rural migrants receive nothing — only the "unusable" court orders - after paying much for the official legal procedures.

\subsection{Provision of Compulsory Education to Rural Migrant Children}

Since 2003, the central government has required local governments to provide compulsory education to rural migrant children in public schools. In reality, local governments failed to achieve this goal. Until now, quite a number of rural migrant children still cannot access public school education (Dong, 2010). This problem is particularly prevalent in coastal cities where rural migrants are concentrated. For example, in Guangzhou, Shenzhen, and Zhongshan, more than half of rural migrant children cannot access local public schools $\left(\mathrm{Li}_{\mathrm{d}}\right.$, 2009). In these areas, local governments tend to set stringent entrance conditions to discourage rural migrants from sending their children to public schools. For example, rural migrants are required to present credentials regarding their residence, employment, social insurance enrollment, birth planning policy compliance, and health conditions etc. If rural migrants fail to provide the required documents, either their children's enrollment is refused in public schools or they are required to pay additional fees $\left(\mathrm{Li}_{\mathrm{d}}, 2009\right.$; Fan \& Peng, 2009).

In this context, many rural migrants send their children to private schools. In some cities like Shanghai, the local government has selected a few private schools and provided them with subsidies, and then commissioned them to offer compulsory education to rural migrant children. In these cases, rural migrant children get subsidized education as those found in public schools (Li \& Peng, 2009). However, in unsubsidized private schools, rural migrants had to bear all the tuition and miscellaneous fees. Moreover, these schools are usually unlicensed and substandard. They are usually short of teachers, classrooms, and teaching facilities, and their hygiene and security conditions can be barely satisfactory (Luo, 2009; Xia, 2006; Dong, 2010).

The financial problems at the local level have been identified as the most important factor of unsatisfactory inclusion of rural migrants in public schools (Fan \& Peng, 2009; Wang \& Fang, 2008; Dong, 2010). Compulsory education is mainly financed by local governments, including the district and municipal governments. Under this system, providing rural migrant children the equal rights to compulsory education means that the local governments need to increase their education expenditures. However, under the current taxation and revenue 
division system in China, local governments only get a small portion of the national revenue even though they have to fund a variety of economic and social programs. Therefore, local governments cannot fully meet the additional requirements in providing compulsory education to rural migrant children in public schools.

Second, some local governments have shown lack of genuine interest in providing rural migrant children with equal education. There are two aspects behind this: (1) While the central government has required local governments to provide compulsory education to rural migrant children, it offers little incentive for local governments to do so. (2) Some local governments seem hesitant that if they increased their education expenditure and provided rural migrant children with equal compulsory education, more migrant children will flow in and they would then have to increase further their education expenditures (Lin \& Su, 2008).

Third, in providing for the actual needs of rural migrants, local governments and public schools face some information and practical barriers that discourage them from including migrant children into public schools (Xia, 2006; $\mathrm{Li}_{\mathrm{d}}$, 2009; Liu \& Zhang, 2008; Lu, 2008). For example, some local governments are not adequately informed on the number and distribution of rural migrant children in their different districts; therefore, they cannot accurately consider their needs when planning for the allocation of educational resources. Furthermore, rural migrants often move from one city to another or from the city to their hometown. In this context, their children move along with their parents or guardians. The local public schools then have to deal with frequent requests for transfers, which add to their difficulty in managing student and class concerns. Moreover, some students leave without prior notice, resulting in a high dropout rate. This places public schools in a disadvantageous position because the Education Bureau demands low dropout rates. In addition, due to their different living environments and the relatively slacked education in rural areas, rural migrant children are not readily integrated with the local student scenario and their study performances seem unsatisfactory. This requires teachers to invest more time and attention on migrant children. In addition, it raises fears among local public schools that to include more migrant children may lower their teaching quality and reputation.

\subsection{Political Participation in Local People's Congresses}

In the second half of the 2000s, a few local governments noted the absence of political rights for rural migrants and attempted to make some improvements on these concerns. Specifically, they explored the possibility of incorporating a few rural migrants into the local people's congresses; some cities like Chongqing even clearly specified the percentage of rural migrants included in the local people's congress (Liao, 2007). Admittedly, democracy in the Western sense is absent in China. The inclusion of rural migrants in local people's congresses may not mean that they can influence policy making substantially. Nonetheless, this move sends out a signal that rural migrants should have equal political rights with local citizens.

However, studies in the past few years revealed the existence of some gaps in restoring rural migrants' political rights. First, the current institutional arrangements for the election of delegates to the people's congresses have hampered the participation of rural migrants in general. One of the most notable problems is that, at present, the number of delegates of local people's congresses is allocated according to the size of formal residents with local hukou. Specifically, under this system, the inclusion of one migrant worker in the local people's congress means that one local candidate is displaced (Hong, 2007). Local governments then had to consider the pressure from local candidates when deciding on the number of rural migrants to be elected into the people's congress. In addition, the designation of voting districts and the registration of voters are also related to the hukou system, and rural migrants still found difficulty in obtaining registration as eligible voters in their respective host cities. For example, to be registered as voters, rural migrants are required to obtain proof of their "eligibility to vote" from the government where their hukou are registered. However, to claim these proofs, they would need to return to their hometowns and undergo cumbersome procedures (Li \& Liu, 2006). Considering the time and financial costs of doing so, many rural migrants have opted to give up their rights to election in their respective host cities.

In addition, even if some rural migrants were elected into local people's congresses, some particular characteristics of rural migrants restrict their abilities in influencing government decision-making and in overseeing local governance (Hong, 2007). One of the most important characteristics of rural-urban migrants in China is that most migrants move in a circular or temporary pattern rather than in a permanent one. However, the term of office for delegates to the people's congress is five years. Consequently, a rural migrant representative might leave before his/her term of service expires. In these cases, the inclusion of rural migrants in local people's congresses has little influence on policymaking and on the welfare of rural migrants in that specific city. In addition, as rural migrants have suffered from low-level education, many know little about laws, government policies, and the role of the people's congress. This lack of formal knowledge affects their ability to assert the 
rights of rural migrants. Faced with these problems, some cities opted to elect to the people's congress those rural migrants who have worked at the managerial level rather than those working "in the frontline," as the former demonstrated much lower mobility and higher levels of knowledge. However, this raises another question: Can these delegates (i.e., rural migrants who have worked at the managerial level) really represent rural-urban migrants, considering only a small number of rural migrants work at the managerial level (Hong, 2007)?

\subsection{The hukou Status and Membership of Rural Migrants in Urban China}

As mentioned earlier, the State has left local governments the option to designate their own conditions for granting local hukou to rural-urban migrants. Particularly, small cities and towns are encouraged to loosen their control on the transfer of hukou of rural migrants. Consequently, small cities and towns, mainly those in Western and Central China relaxed their hukou transfer restrictions and encouraged rural laborers to settle in $\left(\mathrm{Li}_{\mathrm{c}}, 2003\right)$. However, due mainly to the limited employment opportunities, these small cities and towns were unattractive to rural laborers $\left(\mathrm{Li}_{c}, 2003\right)$. In addition, they did not have the capacity to absorb the large number of rural migrants.

In fact, most rural migrants concentrated in a few areas of China where employment opportunities are abundant, such as those in the eastern regions (e.g., Beijing, Tianjin, Shanghai, Zhejiang, Jiangsu, Guangdong, Fujian) and the large and medium-sized cities (The Drafting Group of the Report of Rural-Urban Migrant Workers, 2006, p.5). In these areas, although certain big and medium-sized cities loosened their hukou control since the early 2000 s, the restrictions were only lifted for a few specific subgroups of migrants, such as those coming in for family reunification with a local hukou resident, those who had enough money to invest or buy high-end commercial flats, or those who have obtained higher education (Chan \& Will, 2008; $\mathrm{Li}_{\mathrm{c}}, 2003$ ). Thus, these measures are not relevant to rural-urban migrants, as mostly they have low-level education, come to the cities for employment, work in the low-end labor market and earn the least income.

Since the mid-2000s, some local governments in big and medium-sized cities have responded to the central government's requirement and allowed some outstanding rural migrants, mainly those nominated as "labor models" or "advanced workers," to obtain local hukou. For example, from 2007 to 2009, 200 rural migrant workers have been nominated as labor models in Haerbin. For these rural migrants, the local government loosened the control of hukou transfer and allowed more than half of them to transfer their hukou to Haerbin together with their families (Guo \& Liu, 2009; Zhao, 2009). Nonetheless, one has to note that it is the government that determines the number of rural-urban migrants who are nominated as labor models or advanced workers. Usually, only a very small number of rural migrants can be nominated as labor models or advanced workers. This is not difficult to understand considering that if many people are named as labor models, there is little sense to single them out as "models". To illustrate, in Haerbin, 200 rural migrants were named as labor models from 2007 to 2009, but the total number of rural migrants was approximately 1 million (Zhao, 2009). Obviously, the chance for a rural migrant to be nominated as a labor model is very slim, and this is not an accessible way for a migrant to obtain a local hukou.

In summary, it seems that the local governments in the eastern coastal regions and big and medium-sized cities where large numbers of rural migrants concentrate are still reluctant to indiscriminately accept rural migrants. This reluctance can be understood from two aspects. First, because these cities are the preferred destinations of rural migrants, the local governments are more concerned about the negative impacts from rural migrants on their public infrastructure, social services, and others. Thus, they tend to place a degree of control on the influx of rural migrants to avoid over expansion. Second, hukou control helps local governments to attain development goals better than population management. For example, by allowing migrants who can make certain amounts of investment or who can buy a commercial flat in the host city to get a local hukou, the hukou policy can be used as a tool to stimulate the local estate market and economic growth. A good case in point is offered by Tianjin, one of the biggest metropolitan areas in China. In this city, when the estate market expanded too rapidly in 2007, the local government increased the minimum requirement on the costs of the flat one migrant has to purchase to get a quasi-hukou in order to cool down the market. (Note 1) However, in 2009, as the estate market became sluggish, the government lowered the minimum requirement to invigorate the estate industry ( Liu $_{b}, 2007$; Wang, 2009).

In general, although the central government requires that local governments incorporate long-term rural migrants gradually, there seems to be no standard and accessible means for rural migrants to obtain a local hukou in the coastal regions and in the big- and medium- sized cities. A substantial portion of rural migrants who actually live and work in cities long-term are still denied local hukou and formal membership. 


\section{Action of Rural Migrants: Forms of Resistance}

As Chinese citizens, rural migrants should get equal treatment in the cities. Consequently, how they react to the discriminatory policies had significant implications to the social harmony that the Chinese government aimed to attain.

Generally, rural migrants demonstrated much submissiveness and obedience. Even in the 1980s and 1990s, when the overall policy environment was exclusionary and discriminatory, they tended to endure the unfair treatment rather than take radical actions of resistance. By making reference to the theories on social movement (i.e., the relative deprivation theory and resource mobilization theory), many researchers have suggested that rural migrants in China seemed unable to stage effective social movements to redress their grievances, considering their low levels of organization and their tendency to identify with rural counterparts rather than the local residents (Chen, 2005; Solinger, 1995).

Nonetheless, one has to note that not all rural migrants have readily accepted the unfair treatment. Several kinds of responses and resistances have been observed. First, quite a few rural migrants have opted to commit suicide when their basic rights were infringed. In the early 2000 s, wage delay became a very serious problem among rural migrant workers; some of them found it difficult to provide for their families' basic living expenses. Faced with this problem, suicide was used as a "tool" to exert pressure on employers to get back their wages. For instance, a rural migrant could threaten the employer that he would kill himself in public unless the employer extended the due payment. Actions such as this usually caught public attention, and both local government and employers were then pressured to solve the problems of migrants immediately. This strategy was found rather "effective," such that many migrants opted to simulate the scenario since 2000; this has been described by researchers as a means of safeguarding one's rights "by posing a suicide gesture" (Xu, 2008). In some cases, rural migrants were able to get what they want, albeit involving huge social costs (e.g., long hours of traffic paralysis during the actual suicide attempt). However, when not properly handled, the feigned suicide could result in real suicide $(\mathrm{Xu}, 2008)$.

Second, some rural migrants resort to crimes. Particularly, urban employers often infringed on the rights and interests of rural migrants, and this was often cited as an important factor on migrant crimes. When some rural migrants were unable to receive their wages on time, they stole money or other valuables from employers, and violently kidnapped or even killed their employers - all as a form of revenge. One of the latest cases happened in 2009. A rural migrant suffering from occupational injury killed two managers in anger when the employers refused to give him compensation, as ordered by the court (Yang, 2009). In these cases, the crimes committed by rural migrants are viewed as a form of defense to guard their basic rights and interests (Zhao, 2002).

Third, since the mid-1990s, there have been cases where rural migrants acted in unison to guard their interests. This usually occurs when the interests of a number of rural migrants are collectively infringed (Chan \& Pun, 2009). The migrants may undertake group actions to express their grievances, such as launching strikes, appealing to higher authorities, protesting in front of government headquarters, or blocking roads $\left(\mathrm{Li}_{\mathrm{b}}, 2004\right.$; Halegua, 2008; Chan \& Pun, 2009). For example, in Beijing in 2006, about 80 cases of collective action from rural migrants were launched, taking the form of blocking of roads, and protesting at government offices etc. (Beijing Municipal Commission of Housing and Urban-Rural Development, 2007) Usually these collective actions are controlled before they escalate. However, one cannot deny that the said group actions have undermined China's social stability and harmony.

In addition, from the end of 1990s, there were some generational changes noted among rural-urban migrants in China; the current rural-urban migrants are now more likely to fight back when their rights and interests are infringed (Fu, 2006; $\mathrm{Liu}_{\mathrm{a}}$, 2007; Wang, 2001). Nowadays, rural migrants born from the late 1970s, the 1980s, or even later have comprised majority of the rural migrants in China. Compared to their predecessors, they grew up in an environment of market reform where tremendous economic growth and social transformation can be seen unfolding. Accordingly, they are different from their forerunners in terms of social identity and action. In general, they do not consider themselves as peasants, and tend to compare their lives to urban residents, not to the rural peasants. However, due to institutional discrimination and the subsequent discrimination from urban residents, the rural migrants remain somewhat detached to the urban community. Thus, they do not identify themselves with either rural or urban communities, but as a distinct social group. All these changes point to a higher possibility for rural migrants launching social protests or taking other extreme actions when they are treated unreasonably. But how actually this new generation of rural migrants react to unfair treatments, and to how much degree their action threaten social harmony remains to be closely observed. 


\section{Summary and Suggestions: Governmental Policy for Rural-Urban Migrants and the Attainment of Social Harmony}

In the 1980s and 1990s, rural-urban migrants were denied local hukou and were viewed as temporary residents in their host cities. They had no social and political rights and suffered discrimination from urban administrators. Since 2003, there had been an overall change in the implementation of developmental goals and strategies in China. Social harmony, in particular, was underlined as a goal that is as equally important to economic growth. With this reformulation of developmental goals, in the 2000s, the State identified substantial steps to redress the unequal treatment of rural migrants.

In short, the reforms implemented in the past few years partially removed the inequality between rural migrants and urban residents. However, there is still a gap in terms of the membership status between the two, as reflected in the social and political rights practiced in the host cities. Furthermore, the implementation of the current policies is unsatisfactory. In the face of unfair treatments, although most rural migrants in China behaved quite submissively, some have resorted to different forms of resistance to express their anger and grievances, and the most common of which include committing suicide or crimes, or launching strikes or protesting in public (Halegua, 2008). Furthermore, it has been cautioned that now the new generation of rural laborers has sharpened their consciousness about the inequality between them and the urban residents and is more likely to resist when their rights and interests are harmed (Fu, 2006; $\mathrm{Liu}_{\mathrm{a}}$, 2007).

In summary, the continued prevalence of inequality between rural migrants and urban residents, and the frequent incidents of rural migrants taking extreme actions to express their grievances, undermine social equality, social stability, and social harmony. In the future, further efforts should be considered in terms of enhancing the inclusion of rural migrants, thereby a step to upholding social harmony. First, the implementation of current policies has to be improved. As mentioned earlier, until now, the labor rights of rural migrants remain to be infringed. To address this problem, governments at various levels should accord more formal mechanisms to rural migrants so that they can express their dissatisfaction while existing mechanisms should be improved. Specifically, the financial and time costs of labor dispute arbitrations or lawsuits have to be reduced, legal assistance to rural migrants should be developed, and efficient systems to compel employers to comply with the orders of the Labor Dispute Arbitration Committees or courts should be established. In addition, the central government should guide the local officials to give higher priority to the protection of the labor rights of rural migrants, rather than solely focusing on promoting economic growth.

Second, a transfer system needs to be set up to support and motivate local governments to provide equal compulsory education to rural migrant children (Fan \& Peng, 2009). As mentioned earlier, at present, compulsory education is mainly financed by district and municipal governments. In areas where rural migrants are concentrated, local governments are short on resources, and at times, even lack genuine interests to meet their educational demands. To solve this problem, both the provincial and the central governments need to intervene and provide funding to local governments, in accordance with the number of rural migrant children in these areas.

Third, the participation of rural migrants in the election process in the people's congress in their host cities should be enhanced. This would encourage rural migrants to influence policymaking by formal means, rather than by taking radical actions that harm social harmony. As mentioned earlier, the current procedures that allow rural migrants to register as eligible voters in their respective host cities are costly and cumbersome. Also, the number of rural migrants who can be elected to local people's congresses is not institutionally guaranteed. In the future, these problems should be rectified and detailed regulations for the participation of rural migrants in the people's congress in their host cities should be clarified.

Fourth, the hukou reform needs to be intensified to endow rural migrants the citizenship status equal to local city residents. As previously mentioned, at present, large- and medium-sized cities remain very stringent in terms of conferring local hukou; consequently, most rural migrants are unable to acquire the hukou. This may be tolerable for rural migrants who merely work in the cities temporarily; however, for others who have worked and lived in cities for a long time already, the hukou problem needs to be remedied. Since the mid-2000s, about 24.7 million (i.e., more than one-fifth of total rural migrants) have moved their families to the cities and have lived there in long-term (The Drafting Group of the Report of Rural-Urban Migrant Workers, 2006, p.11). These migrants are de facto permanent residents, but are denied full social entitlements and political rights just because they have no local hukou. This second-class citizenship status is incongruent with the orientation of social equality and justice in a harmonious society. In the future, urgent reforms on the hukou policy should be ensured to allow these migrants to obtain the proper local hukou. 
Overall, from the perspective of government policies for rural migrants, the policy reforms and implementation in the 2000s are far from adequate in terms of achieving equality and in tackling the potential problems that may lead to social unrests. To promote social harmony, the government needs to ensure these two aspects: (1) improve the regulations governing social and political rights of rural migrants in their respective host cities, and (2) adjust the relation between the central and local governments so that the latter are able to and are encouraged to equally serve the rural migrants.

\section{References}

Aspalter, C. (2006). The East Asian welfare model. International Journal of Social Welfare, 15, 290-301.

Beijing Municipal Commission of Housing and Urban-Rural Development. (2007). Emergency action for rural migrants' collective action in the construction industry. [Online] available: http://www.bjjs.gov.cn/publish/portal0/tab1248/info44688.htm (November 24, 2009) [in Chinese].

Chan, C. K.-C., \& Pun, N. (2009). The Making of a New Working Class? A Study of Collective Actions of Migrant Workers in South China. China Quarterly, 198, 287-303.

Chan, K. W., \& Will, B. (2008). Is China Abolishing the Hukou System? China Quarterly, 195, 582-606.

Chen, Y. F. (2005). 'Peasant-labour': System and identity. Sociology Research, 3, 119-132, 244. [in Chinese]

China Communist Party Central Committee (CCPCC). (2004). Decisions about promoting the governance capacity of CCP. [Online] available: http://www.china.com.cn/zhuanti2005/txt/2004-09/27/content_5668376.htm (May 27, 2009) [in Chinese].

CCPCC. (2005). Opinions about making the 11th Five-Year Plan of national economic and social development. [Online] available: http://www.cycnet.com/zuzhi/ywdd/files/ywdd20051019.htm (July 31, 2008) [in Chinese].

Dong, J. (2010). Neo-Liberalism and the Evolvement of China's Education Policies on Migrant Children's Schooling. Journal for Critical Education Policy Studies, 8(1), 137-160.

Fan, X. Z., \& Peng, P. (2009). Thoughts about the financing mechanism for the education of rural migrants' children. China Education Journal, 3, 11-13, 25. [in Chinese].

$\mathrm{Fu}, \mathrm{P}$. (2006). Floating and struggling: the living conditions of youth rural-urban migrant workers. Survey World, 9, 20-25. [in Chinese].

Guo, Q., \& Liu, C. J. (2009). Haerbin government loosing the conditions of hukou transfer for rural migrant Labour Models. [Online] available: http://www.gov.cn/jrzg/2009-06/29/content_1352666.htm (January 04, 2010) [in Chinese].

Halegua, A. (2008). Getting Paid: Processing the Labor Disputes of China's Migrant Workers. Berkeley Journal of International Law, 26(1), 254-322.

Hong, F. (2007). The factors inhibiting the influence of rural-urban migrant delegates in People's congress. Journal of Citizens, 11, 13-14. [in Chinese].

Knight, J., Song, L., \& Jia, H. (1999). Chinese rural migrants in urban enterprises: Three perspectives. Journal of Development Studies, 35(3), 73-104.

$\mathrm{Li}_{\mathrm{a}}$, B. (2005). Urban social change in transitional China: A perspective of social exclusion and vulnerability. Journal of Contingencies and Crisis Management, 13(2), 54-65.

$\mathrm{Li}_{\mathrm{b}}$, Q. (2004). Deprivation theories and the problem of rural-urban migrants in China. Academic World, 4, 7-22. [in Chinese].

$\mathrm{Li}_{\mathrm{c}}$, R. J. (2003). The hukou status of the population and the reform by regions. China Population Sciences, 3 , 7-15. [in Chinese].

$\mathrm{Li}_{\mathrm{d}}$, W. B. (2009). Empirical research on the factors affecting the provision of compulsory education to rural migrants' children. Jianghan Forum, 7, 15-18. [in Chinese].

Li, A. M., \& Peng, W. (2009). 90\% of migrants' children get free compulsory education in Shanghai. [Online] available: http://news.xinhuanet.com/edu/2009-10/10/content_12204786.htm (April 1, 2010) [in Chinese].

Li, Y. S., \& Liu, Y. X. (2006). Social Policy and Social Protection of Rural-Urban Migrant Workers. Social Science Research, 6, 100-105. [in Chinese].

Liao, C. Y. (2007). To include rural-urban migrants in people's congresses-the trend of a legal society. Journal of Citizens, 11, 9-10. [in Chinese]. 
Lin, J. Y., \& Su, L. Y. (2008). How to finance the education of rural migrants' children should be clarified. Shanghai Agricultural Technology, 3, 7-8. [in Chinese].

$\mathrm{Liu}_{\mathrm{a}}$, C. B. (2007). The replacement of Subsistence Ration. Fujian Forum, 7, 132-135. [in Chinese].

$\mathrm{Liu}_{\mathrm{b}}$, L. P. (2007). The change of "Blue-Stamp hukou" in Tianjin putting migrants from Hebei in dilemmas. [Online] available: http://www.022net.com/2007/5-1/416854112619382.html (August 17, 2008) [in Chinese].

Liu, X. M., \& Zhang, L. M. (2008). An discussion of the education provision to rural migrants' children on the local level. China Collective Economy, 6, 186-187. [in Chinese].

$\mathrm{Lu}, \mathrm{X}$. B. (2008). The research on the practice of education-provider to rural migrants' children. Theory and Reform, 4, 66-70. [in Chinese].

Luo, T. Y. (2009). The education of rural migrants' children and policy suggestions. Social Scientist, 1, 116-121. [in Chinese].

Ramesh, M. (2004). Social Policy in East and Southeast Asia: Education, Health Housing and Income Maintenance. Routledge-Curzon, London, (p.153).

Shen, X. (2003). With regard to the case that a college graduate die in the confinement station in Guangzhou: 13 suspects were arrested, South City Daily. [Online] available: http://news.sina.com.cn/c/2003-05-13/09471052550.shtml (March 3, 2009) [in Chinese].

Solinger, D. J. (1995). China's urban transients in the transition from socialism and the collapse of the communist 'Urban Public Goods Regime'. Comparative Politics, 27(2), 127-146.

State Council. (2006, No. 5). Recommendations to solve the problem of rural-urban migrant workers. [Online] available: http://www.gov.cn/jrzg/2006-03/27/content_237644.htm (November 17, 2008) [in Chinese].

State Council General Office. (2003, No. 1). Announcement about Improving Management and Services Regarding Rural Labors Working in cities. [Online] available: http://search.gd.gov.cn/detail?record=16\&channelid=16317 (April 6, 2010) [in Chinese].

The Drafting Group of the Report of Rural-Urban Migrant Workers. (2006). Study report of rural-urban migrant workers. In The project group of the State Council Research Center (Ed.), Survey report of rural-urban migrant workers in China. Beijing: Yanshi Press, pp. 4-11 [in Chinese].

Tong, L. H., \& W. D. Xiao. (2005). The survey report about the costs for rural-urban migrant workers to guard their interests. [Online] available: http://www.chineselawyer.com.cn/pages/2005-9-29/s31553.html (June 13, 2009) [in Chinese].

Wang, C. G. (2001). Social identity of new generational of rural-urban migrant workers and the rural-urban relations. Sociology Research, 3, 63-76. [in Chinese].

Wang, F.-L. (2004). Reformed Migration Control and New Targeted People: China's Hukou System in the 2000s. China Quarterly, 177, 115-132.

Wang, J. X., \& Fang, H. B. (2008). The fiscal incentive mechanism for the education of rural migrants' children. Journal of Huazhong Normal University, 47(4), 10-15. [in Chinese].

Wang, Y. B. (2009). Tianjin: "blue-stamp hukou" to support the estate market and to what degree it is effective? [Online] available: http://sh.eastday.com/qtmt/20090223/u1a540084.html (June 24, 2009) [in Chinese].

Xia, C. (2006). Migrant Children and the Right To Compulsory Education in China. Asia-Pacific Journal on Human Rights \& the Law, 7(2), 29-74.

$\mathrm{Xu}, \mathrm{X}$. (2008). Committing suicide to strive for rights-Rural migrants fighting with their lives in the social transformation. Case Studies in China's Institutional Change, 6, 255-305. [in Chinese].

Xu, Q., Guan, X., \& Yao, F. (2011). Welfare program participation among rural-to-urban migrant workers in China. International Journal of Social Welfare, 20(1), 10-21.

Yang, G. S. (2009). Why the rural-urban migrant worker who killed the managers have become the hero in internet. [Online] available: http://news.sina.com.cn/pl/2009-06-18/073218042799.shtml (June 18, 2009) [in Chinese].

Zhao, S. (2002). Conflicts and governance reform--research about the management of rural migrants. [Online] available: 
http://218.246.21.135:81/gate/big5/www.drcnet.com.cn/drcnet.channel.web/expert/showdoc.asp?doc_id=137360 (June 10, 2009) [in Chinese].

Zhao, Z. Y. (2009). The 60 thousands of rural migrants' children getting equal treatments with the local children in Haerbin. [Online] available: http://www.china.com.cn/news/gongyi/2009-12/03/content_19003520.htm (January 04, 2010) [in Chinese].

Zheng, G. C., \& Huang, L. R. L. (2006). Rural-urban migrant workers in China-issue and social protection: theoretical judgment and policy thoughts. Journal of Renmin University of China, 6, 2-13. [in Chinese].

Zheng, G. H. (2005). Injured migrant workers: A de-powered social group. Sociology Research, 3, 99-118. [in Chinese].

Note

Note 1. The migrants who purchase a high-end commercial flat in Tianjin do not get a local hukou immediately but a quasi-hukou, namely the Blue-Stamp hukou. The Blue-Stamp hukou is a transitional hukou booklet that carries a blue stamp different from the red stamp on formal hukou booklets. However, after two years, the Blue-Stamp hukou can be converted to a formal hukou booklet with a red stamp. 